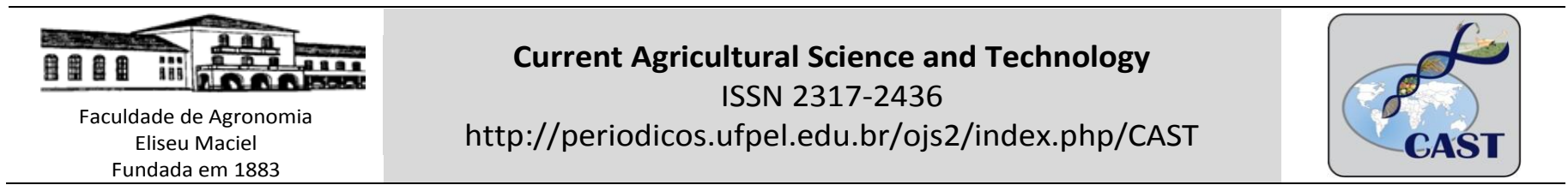

\title{
Postharvest treatments to mitigate the internal browning in 'Bartlett' pears
}

Lucimara Rogéria Antoniolli $^{1^{*}}$, Ana Beatriz Costa Czermainski ${ }^{1}$, Moises Zucoloto ${ }^{2}$, Dalmo Lopes Siqueira ${ }^{3}$

\footnotetext{
${ }^{1}$ Brazilian Agricultural Research Corporation/Embrapa Grape and Wine, P.O. box 130 - 95700-000 - Bento Gonçalves, RS - Brazil.

${ }^{2}$ Universidade Federal do Espírito Santo (UFES), P.O. box 16 - 29500-000 - Alegre, ES - Brazil.

${ }^{3}$ Universidade Federal de Viçosa, Peter Henry Rolfs Avenue - 36570-000 - Viçosa, MG - Brazil.
}

*Corresponding author: L.R Antoniolli

E-mail: lucimara.antoniolli@embrapa.br

\section{ABSTRACT}

Internal browning is an important disorder in pear fruit which can lead to economic losses. Pears (Pyrus communis L. cv. Bartlett) were harvested at early harvest maturity of $90 \mathrm{~N}$ from a commercial orchard in southern Brazil. Methyl jasmonate, ethanol, and 1-methylcyclopropene vapor treatments were carried out for 24 hours in order to mitigate the internal browning disorder. Fruit were stored for up to 150 days at $0 \pm 1{ }^{\circ} \mathrm{C}$ and $90 \pm 5 \% \mathrm{RH}$. Pears exhibited internal browning in $37 \%$ of the control samples after 90 days of cold storage. However, no internal browning symptoms were observed in the 1-MCP treatment. The first symptoms in 1-MCP samples were noticed after 120 days of cold storage (12\%) and reached $100 \%$ in five days at room temperature. 1-MCP-treated pears showed flesh firmness values of $82 \mathrm{~N}$ after 90 days of cold storage and $18.7 \mathrm{~N}$ when they were removed from the cold storage and kept at $20{ }^{\circ} \mathrm{C}$. The greatest acceptance index was attributed to 1MCP pears after 90 days at $0 \pm 1{ }^{\circ} \mathrm{C}$ followed by 5 days at $20 \pm 1{ }^{\circ} \mathrm{C}$ (89.35). High acceptance indexes were attributed to MeJa (77.95) and control pears (76.40) after 30 days in cold storage followed by 5 days at room temperature. 1-MCP $\left(0.3 \mu \mathrm{L} \mathrm{L}^{-1}, 24\right.$ hours at $0 \pm 1{ }^{\circ} \mathrm{C}$ ) treatment delays ripening and mitigates the internal browning in early harvested 'Bartlett' pears, that can be stored for up to 90 days at $0 \pm 1{ }^{\circ} \mathrm{C}$.

Keywords: Pyrus communis L.; cold storage; ethanol; 1-methylcyclopropene; methyl jasmonate; physiological disorder.

\section{INTRODUCTION}

Among the temperate fruits, pear is the third most consumed fruit in Brazil. More than 200.000 tons are consumed annually, from which $90 \%$ are imported from Argentina, Chile and Portugal.

Internal browning is an important disorder in several pear fruit cultivars which can lead to economic losses (Franck et al., 2007). The disorder causes brown to black discoloration of the seed cavity and may extend into surrounding portions of the flesh (Chen, 1990).

The range of firmness values recommended as indicators of harvest maturity is 85 to $98 \mathrm{~N}$ for 'Bartlett' pears (Sugar and Powers, 1994). The optimum temperature stated for 'Bartlett' pears in the "Recommendations for 
Maintaining Postharvest Quality" from University of California is from -1 to $0^{\circ} \mathrm{C}$ (Mitchan et al., 2013), but the storage of these fruit is typically limited to 60-90 days in air, even under ideal storage conditions at $-1{ }^{\circ} \mathrm{C}$ (Ju et al., 2001). In most cases, the end of storage life is due to the onset of physiological disorders, particularly superficial scald and internal browning. Ethylene produced by the fruit can exacerbate these disorders, and can also cause premature yellowing and softening during storage (Ju et al., 2001).

Methods used to delay the ripening process and extend the storage life or promote biosynthesis of secondary metabolites may have a direct or indirect effect on the disorder incidence. 1-Methylcyclopropene (1-MCP) is an ethylene action inhibitor and has been evaluated for its ability to extend the storage life of pears and delay ripening. The postharvest application of 1MCP decreases softening, internal browning, color development, storage scald, respiration rate and ethylene production in pear fruit (Argenta et al., 2003; Kubo et al., 2003; Ekman et al., 2004; Trinchero et al., 2004). Postharvest ethanol (EtOH) treatment has many beneficial effects on horticultural crops, including the regulation of ripening, and the reduction of chilling injury and apple scald (Pesis, 2005). Exposure to ethanol vapors at $\leq 6 \mathrm{~mL} \mathrm{~kg}^{-1}$ fruit for up to $6 \mathrm{~h}$ inhibited the ripening of mature-green tomatoes by 7 days but failed to inhibit the ripening of other climacteric fruits (Ritenour et al., 1997). Methyl jasmonate (MeJa) is a naturally occurring plant growth regulator that plays an important role in promoting biosynthesis of secondary metabolites (Creelman and Mullet, 1997). Postharvest MeJa application resulted in increased anthocyanin contents and antioxidant activities (phenolics and ascorbic acid) in apples (Rudell et al., 2002).

This study was carried out to determine if 1-MCP, EtOH and MeJa applied as a postharvest vapor treatments could mitigate the internal browning in 'Bartlett' pears.

\section{MATERIAL AND METHODS}

\section{Plant material}

Pears (Pyrus communis L. cv. Bartlett) were harvested at early harvest maturity of $90 \mathrm{~N}$ from a commercial orchard in São Francisco de Paula $\left(29.45^{\circ} \mathrm{S}, 50.58^{\circ} \mathrm{W}\right), \mathrm{RS}$, Brazil. Defect-free pears of uniform size were selected before being used for treatments.

\section{Treatments}

Treatments were carried out immediately after harvesting. Pears were randomly divided into four lots of 364 fruit. Fruit from each lot were placed into very well sealed 293 L plastic containers. Control fruit were kept with no volatile treatment for $24 \mathrm{~h}$ at $0 \pm 1{ }^{\circ} \mathrm{C}$. Methyl jasmonate (MeJa) $20.69 \mu \mathrm{L} \mathrm{L}^{-1}$, ethanol (EtOH) $6000 \mu \mathrm{Lg}^{-1}$ and 1-Methylcyclopropene (1-MCP) $0.3 \mu \mathrm{L} \mathrm{L}^{-1}$ vapor treatments were carried out for 24 hours at $0 \pm 1{ }^{\circ} \mathrm{C}$ for $1-\mathrm{MCP}$ and at $20 \pm 1{ }^{\circ} \mathrm{C}$ for MeJa and EtOH treatments. MeJa and $\mathrm{EtOH}$ treatments were applied as a liquid lamina on the bottom of the container and 1-MCP was applied as recommended by SmartFresh ${ }^{\circledR}$. There was no contact between fruit and liquid compounds. All the compounds were allowed to spontaneously vaporize inside the containers. Afterwards, the containers were opened and ventilated. The fruit (6 per replicate) were labeled and weighed prior to transfer to molded trays inside opened plastic boxes. Fruit were randomly stored at $0 \pm 1{ }^{\circ} \mathrm{C}$ and $90 \pm 5 \%$ RH for up to 150 days.

\section{Quality analysis}

Four replicates (6 fruit per replicate) were assessed before the treatments and another four immediately following the volatile exposure period. Pears were assessed after $30,60,90,120$ and 150 days of cold storage and after five days of ripening at room temperature $\left(20 \pm 1^{\circ} \mathrm{C}\right)$. The internal browning incidence was visually evaluated and recorded as the percentage of the total evaluated fruit affected by the disorder. Flesh firmness was measured objectively on two 
sides of each fruit using a FTA - Fruit Texture Analyzer (Güss) fitted with an $8 \mathrm{~mm}$ probe after a thin slice of skin was removed. Skin color was assessed with a tri-stimulus color difference meter (Minolta CR 300) and expressed as $L^{*}, a^{*}$, and $b^{*}$ values. Chroma and Hue angle were calculated as $C=\left(a^{* 2}+b^{* 2}\right)^{1 / 2}$ and Hue $=\tan ^{-1}$ $\left(b^{*} / a^{*}\right)+k\left(k=180\right.$, if $a^{*}<0 ; k=360$ if $b^{*}<0$ and $k=0$ if both are positive), respectively. Starch index determination was performed as Avelar and Rodrigues (1999) with modifications. A $1 \mathrm{~cm}$ slice was taken from the equatorial region of each fruit and dipped in the iodine-potassium iodide solution for $30 \mathrm{sec}$. After $15 \mathrm{~min}$ fruit were rated subjectively using the chart proposed by Avelar and Rodrigues (1999). Seed color was rated on a scale of 1-3, where 1 , immature beige color seed and 3, mature dark color seed. Soluble solids content was measured on juice using a hand-held digital Atago refractometer (0-20\%). Titratable acidity was measured by titrating juice with $0.1 \mathrm{~N}$ $\mathrm{NaOH}$ to a $\mathrm{pH}$ 8.1. Results were presented as percentage malic acid. Weight loss was measured between post treatment time and removal from the cold room and between removal from the cold room and the end of ripening at room temperature. Peduncle was visually rated on a scale of 1-5, where 1, non-dehydrated; 2, dehydrated at the cut end; 3, $50 \%$ dehydrated; 4, $90 \%$ dehydrated and 5, totally dehydrated.

\section{Sensory analysis}

For sensory analysis, fruit were presented to at least 30 non-trained panelists per session who were orientated on sensory analysis of pears. Assessments took place in individual tasting booths. The pears were sliced using a pear corer slicer and the samples were presented with the intact skin. The preparation was performed just a few minutes before tasting to avoid oxidative enzymatic browning on the cut surface of the fruit. Drinking water was provided for cleansing the palate between samples. A difference-fromcontrol test was carried out as described by Meilgaard et al. (1999). Each panelist was given a labeled control sample and four coded samples. Within the coded samples, the control was presented as a blind-control, and the panelists were alerted to this. This test is used to determine if there is some difference between one or more test samples and the control, and to measure its size. A rating scale of $0-9$, where 0 indicates no difference, and 9, a huge difference, was used to measure the difference size among test samples. An acceptance test was carried out as described by Ferreira et al. (2000). Four randomized coded samples were assessed per session and all the panelists assessed the same number of samples. A standard 7-point hedonic scale was used, where 1 , dislike very much; 2 , dislike moderately; 3 , dislike slightly; 4, neither like nor dislike; 5, like slightly; 6, like moderately and 7, like very much. Assessors were also asked to record their observations about each sample.

Variables-response and statistical analysis

The experiment was analyzed according to a completely randomized model considering the samples were drawn, identified and treated with no restrictions to randomization. The unifactorial model (one-way design) was used and each treatment was composed by the combination of the volatile treatment, cold storage and ripening at room temperature. Flesh firmness, soluble solids, titratable acidity and weight loss were analyzed by ANOVA, after the assumptions were verified. The decomposition of the significance effect of treatments ( $F$ test) was obtained by orthogonal contrast ( $t$ test), respecting the structure of the treatment factors. The principal components analysis (PCA) to the color-related variables ( $L^{*}, C$ and Hue) was used to discriminate the treatments through $2 \mathrm{D}$ plots, considering the magnitude of the variation explained by the adjusted PC functions. Frequencies ( $\mathrm{Fi}, \mathrm{i}=1,2, \ldots, 7$ ) into the hedonic scales classes resulted from the sensory evaluation of samples per treatment by at least 30 panelists. An acceptance index, represented by la, which amplitude ranges from 0 (non-acceptance) to 100 (maximum acceptance) 
came from the distribution of frequencies of each treatment. This measure, adapted from Czermainski (1999), was adopted in order to associate the treatments to a quantitative response that allowed comparison and calculation of the differences among them in a continuous scale. Qualitative characteristics data relating to the visual aspects of seeds and peduncles were treated descriptively. The inferential analyses were performed with GLM and PRINCOMP procedures of SAS (Statistical Analysis Systems, version 9.2).

\section{RESULTS}

Pears were discarded when the internal browning incidence reached at least $50 \%$ of the total assessed fruit, including the four replicates from each treatment. Quality data obtained from pears after the cold storage which had a $100 \%$ internal browning incidence when transferred to room temperature were not considered.

Pears exhibited internal browning in the control samples after 90 days of cold storage, as well as in the samples treated with MeJa and EtOH. However, no internal browning symptoms were observed in 1-MCP-treated fruit after 90 days of cold storage. All the fruit, except for 1MCP samples, had an increase in the internal browning incidence when transferred to room temperature after 90 days of cold storage. The first symptoms in 1-MCP samples were noticed after 120 days of cold storage (12\%) and reached $92 \%$ after 150 days of storage. Control and MeJa treatment exhibited $100 \%$ internal browning after 120 days of cold storage. All the EtOH and 1MCP samples developed the disorder when fruit were kept for 5 days at room temperature, independently of the incidence of internal browning at the end of cold storage (Figure 1A).

The F-test pointed to differences among treatments for flesh firmness, soluble solids, titratable acidity and weight loss $(p<0.001)$. The contrast estimates were obtained by difference among the average values from the involved treatments (Table 1).

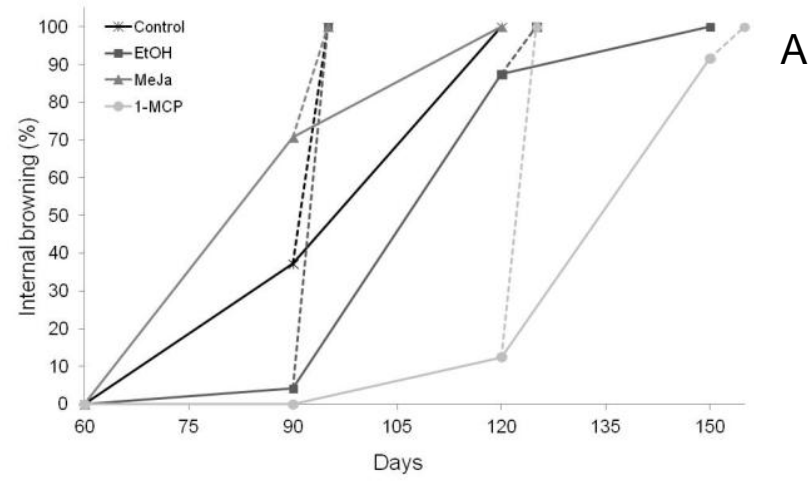

A

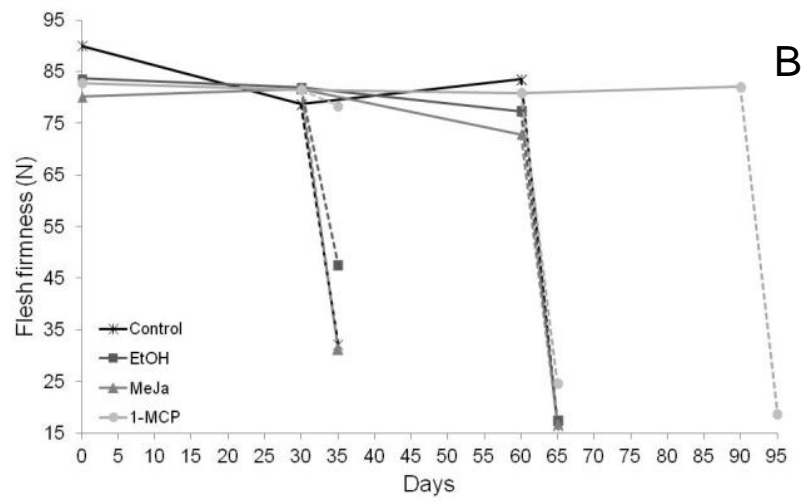

Figure 1. Incidence of internal browning $(A)$ and flesh firmness (B) in 'Bartlett' pears subjected to different volatile treatments, kept at $0 \pm 1{ }^{\circ} \mathrm{C}$ and $90 \pm 5 \% \mathrm{RH}$ for up to 150 days (solid lines) and transferred to room temperature for 5 days to ripen (dashed lines).

1-MCP was the only treatment that retarded softening (Table 1). There was no change in firmness among 1-MCP-treated fruit after 5 days ripening at $20{ }^{\circ} \mathrm{C}$ following 30 days of cold storage, but a marked decrease was observed for control, MeJa and EtOH samples subjected to the same temperature regime (Table 1 and Figure 1B). Control samples (32.1 N) and MeJa-treated pears $(31.1 \mathrm{~N})$ showed the softest flesh firmness after 5 days of ripening, but they were much higher than the recommended firmness for eating (10-18 N). After 60 days of cold storage followed by 5 days at room temperature only the pears treated with 1MCP had not reached the firmness for eating, 
Table 1. Contrast estimates for flesh firmness, soluble solids, titratable acidity, and weight loss.

\begin{tabular}{|c|c|c|c|c|c|c|c|c|c|}
\hline \multirow[t]{3}{*}{ Con } & \multirow[b]{3}{*}{ Control vs EtOH } & \multicolumn{8}{|c|}{ Difference among averages and significance ${ }^{(1)}$} \\
\hline & & \multicolumn{2}{|c|}{ Flesh firmness } & \multicolumn{2}{|c|}{ Soluble solids (SS) } & \multicolumn{2}{|c|}{ Titratable acidity (TA) } & \multicolumn{2}{|c|}{ Weight loss $^{(2)}$} \\
\hline & & -0.80 & ns & -0.58 & $* *$ & 0.02 & $* *$ & 0.02 & ns \\
\hline & Control vs 1-MCP & -3.33 & $* *$ & -0.64 & $* *$ & -0.03 & $* *$ & -0.65 & $*$ \\
\hline \multirow[t]{3}{*}{ Control } & $(0+0)$ vs $(30$ and 60$)$ & 36.53 & $* *$ & -0.81 & $* *$ & 0.02 & ns & & \\
\hline & $(30+0)$ vs $(30+5)$ & 49.75 & $* *$ & -0.43 & ns & 0.02 & ns & -0.93 & ns \\
\hline & $(60+0)$ vs $(60+5)$ & 66.96 & $* *$ & 0.15 & ns & -0.03 & $* *$ & -3.71 & $* *$ \\
\hline \multirow[t]{2}{*}{$\mathrm{EtOH}$} & $(0+0)$ vs $(30$ and 60$)$ & 27.65 & $* *$ & -1.59 & $* *$ & 0.003 & ns & & \\
\hline & 30 vs 60 & 17.35 & $* *$ & 0.05 & ns & -0.06 & $* *$ & -3.35 & $* *$ \\
\hline \multirow{3}{*}{ MeJa } & 30 vs 60 & 11.59 & $* *$ & -0.11 & ns & -0.08 & $* *$ & -5.99 & $* *$ \\
\hline & $(30+0)$ vs $(30+5)$ & 50.55 & $* *$ & -0.46 & ns & -0.02 & ns & -0.27 & ns \\
\hline & $(60+0)$ vs $(60+5)$ & 56.10 & $* *$ & 0.33 & ns & 0.003 & ns & -4.09 & $* *$ \\
\hline \multirow[t]{5}{*}{ 1-MCP } & $(0+0)$ vs $(30,60$ and 90$)$ & 21.77 & $* *$ & -1.38 & $* *$ & -0.06 & $* *$ & & \\
\hline & 30 vs (60 and 90) & 28.39 & $* *$ & -0.36 & ns & -0.11 & $* *$ & -4.04 & $* *$ \\
\hline & 60 vs 90 & 2.37 & ns & 0.13 & ns & 0.02 & $* *$ & -3.00 & $* *$ \\
\hline & $(30+0)$ vs $(30+5)$ & 3.20 & ns & 0.03 & ns & 0.02 & ns & -1.28 & $*$ \\
\hline & $(60+0$ vs $(60+5)$ & 56.30 & $* *$ & -0.28 & ns & -0.01 & ns & -5.66 & $* *$ \\
\hline
\end{tabular}

${ }^{(1)}$ Significance by $t$ test: "ns": not significant, one asterisk: $p<0.05$, and double asterisk: $p<0.01$.

${ }^{(2)}$ The weight loss was obtained in relation to the control $(0+0)$. The control in the three first contrasts corresponds to 30 and 60 days in cold storage

which they only achieved after 90 days of storage followed by 5 days at $20^{\circ} \mathrm{C}$ (Figure 1B).

The most important polar coordinate of skin color was the Hue angle. Values ranged from 102.5 (Control) to 98.4 (EtOH) after the $24 \mathrm{~h}$ exposure treatment, but these were visually indistinguishable from the before-treatment Hue angle (101.0). Fruit from all treatments exhibited a decrease in Hue values of the skin during cold storage. 1-MCP pears reached 86.3 after 90 days of cold storage. Sharp decreases in Hue angle were noticed when fruit were removed from cold storage after being kept for 30 and 60 days and transferred to room temperature, except for 1-
MCP samples stored up to 30 days in a cold room (Figure 2).

Principal component analysis (PCA) allowed the visualization of the three color attributes in reduced dimension. The principal components 1 (PC1) and 2 (PC2), respectively, accounted for $76 \%$ and $19 \%$ of the total variability. Groups of treatments were observed according to the time (cold storage and ripening at room temperature) and not according to the volatile treatment, highlighting $(0+0)$ and $(30+0)$. As the cold storage increased ( $\geq 60$ days) those treatments had a gradual displacement toward the right side of the graph (smallest Hue and 


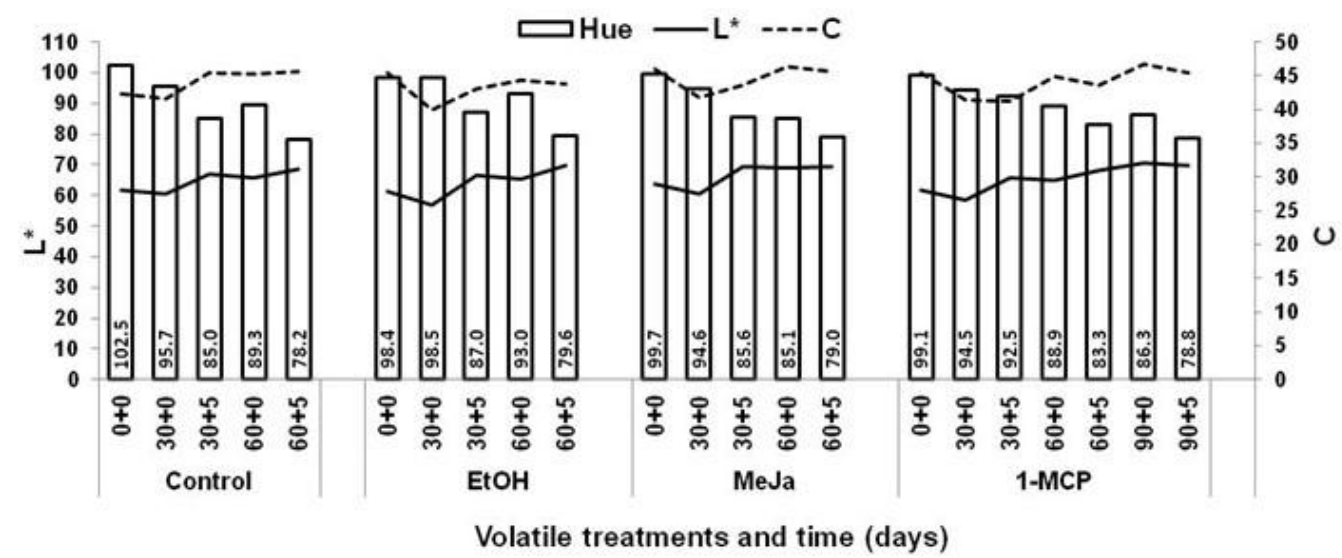

Figure 2. Skin color ( $\mathrm{L}^{*}, \mathrm{C}$ and Hue angle) of 'Bartlett' pears subjected to different volatile treatments, kept at $0 \pm 1{ }^{\circ} \mathrm{C}$ and $90 \pm 5 \% \mathrm{RH}$ for up to 90 days and transferred to room temperature for 5 days to ripen.

greatest $\mathrm{L}^{*}$ and $\mathrm{C}$ ). The ripening at room temperature established two groups of treatments, above and below the zero line to PC2 ( $L^{*}$ and $C$ attributes had more influence than Hue angle) (Figure 3).

Changes in starch indexes were observed immediately after the treatment and after 30 days of cold storage. Keeping the fruit at room temperature after this period was sufficient to allow starch breakdown to reach the maximum possible value on the scale (from 1 to 10) proposed by Avelar and Rodrigues (1999), which means the starch content in the pears is almost null. All the assessed fruit showed index 2 before being exposed to the different treatments. Immediately after the treatment, 1-MCP samples showed a mean starch index 2.3, which was lower than the control (3.1), MeJa (3.6), and EtOH (3.7) treated samples (data not shown). Furthermore, the maximum scale value observed in pears treated with 1-MCP was 4 ( $8 \%$ of the total fruit), whereas $4 \%$ of the control and $8 \%$ of the $\mathrm{EtOH}$ samples reached 5 on the scale. $17 \%$ and $8 \%$ of MeJa samples achieved the values 5 and 6, respectively, after the treatment (Figure 4). After 30 days of cold storage, EtOH samples showed a mean starch index of 9.1, lower than those observed in the samples subjected to the other

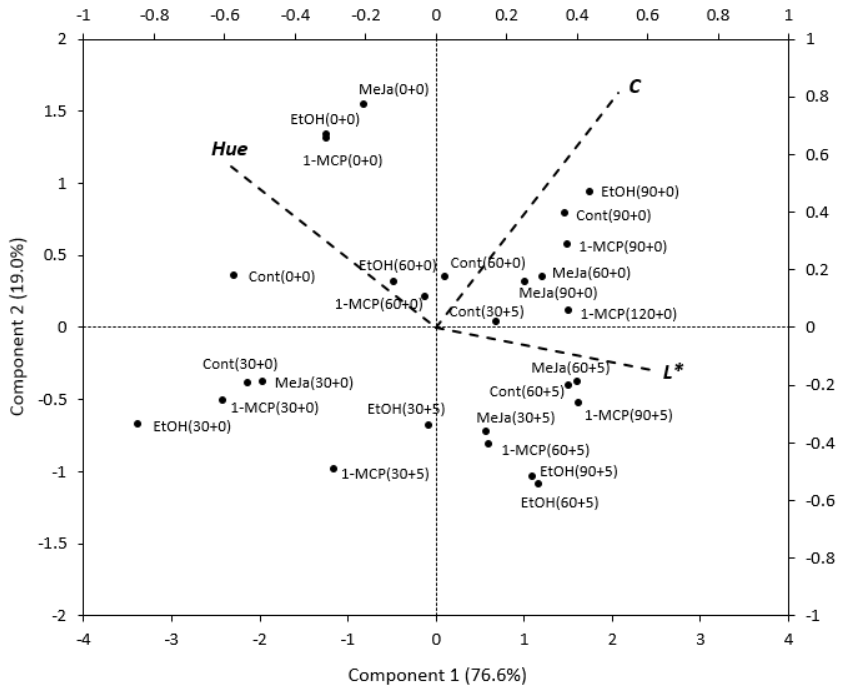

Figure 3. Biplot displaying results of the PCA observations or treatments (dots, principal axes) and variables loadings (vectors, secondary axes) - for color data of 'Bartlett' pears.

treatments that ranged between 9.7 and 9.9 (data not shown). $79 \%$ of the EtOH samples exhibited values of 8 and 9 , whereas at least $70 \%$ of control and samples treated with MeJa and 1-MCP reached the maximum value on the scale (Figure 4).

Changes in the color of the seeds were first noticed when pears had been subjected to 30 days of cold storage and then ripened at room 

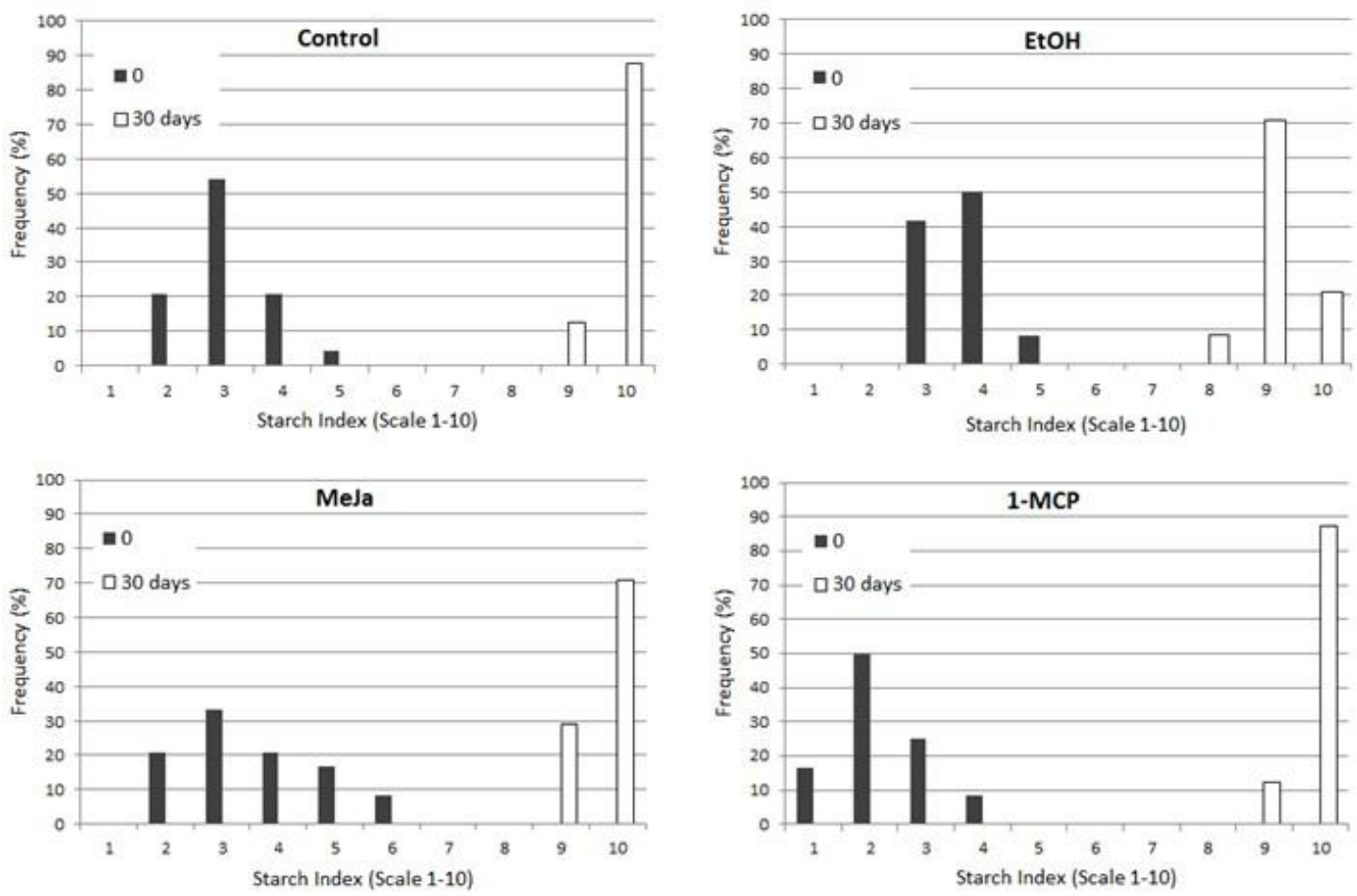

Figure 4. Starch index in 'Bartlett' pears subjected to different volatile treatments, immediately after treatment (black bars) and after 30 days of subsequent storage at $0 \pm 1{ }^{\circ} \mathrm{C}$ and $90 \pm 5 \% \mathrm{RH}$ (white bars).

showed the highest number of fruit with seeds in temperature for 5 days. The control treatment a transitional color (87\%), followed by $1-\mathrm{MCP}$ and MeJa samples. EtOH-treated fruit had only $12 \%$ of the seeds in this condition. After 60 days of cold storage, all the control and MeJa-treated samples had reached the intermediate value (2) of the scale and there was no progression in the color of the seeds when fruit were kept at room temperature for up to 5 days. EtOH treatment delayed the color changes of the seeds up to 60 days of cold storage, but no immature seed was observed when fruit were transferred to room temperature. 1-MCP-treated fruit showed $100 \%$ of mature seeds (3) when they were transferred to room temperature after being kept for 90 days in the cold room (Figure 5).

All the treatments resulted in an increase in the soluble solid content of fruit, but no changes were observed following transfer to room temperature except for EtOH-treated fruit, which increased by $1.2{ }^{\circ} \mathrm{Brix}$ during 5 days of ripening after 30 days of cold storage to reach $12.7^{\circ}$ Brix. The average SS contents ranged from 10.6 ${ }^{\circ}$ Brix immediately after the treatments to $12.7^{\circ}$ Brix by the end of the storage (Table 1 and Figure 6A). Compared to control samples, 1-MCP treatment provided higher titratable acidity in the fruit during the whole storage period, whereas the EtOH showed an opposite effect (Table 1). After 60 days of cold storage, EtOH-treated pears that were transferred to room temperature had a decrease in titratable acidity content that was not observed in the other samples. The average TA contents ranged from $0.15 \%$ to $0.29 \%$ malic acid during the entire storage (Table 1 and Figure 6B).

Weight loss was most evident after 60 days of cold storage for control, EtOH- and MeJatreated fruit. 1-MCP-treated fruits exhibited a much smaller weight loss after 60 days of cold storage, but their weight loss subsequently increased sharply to reach $9 \%$ by 90 days of cold storage. Additional weight losses occurred when fruit were transferred to room temperature. 

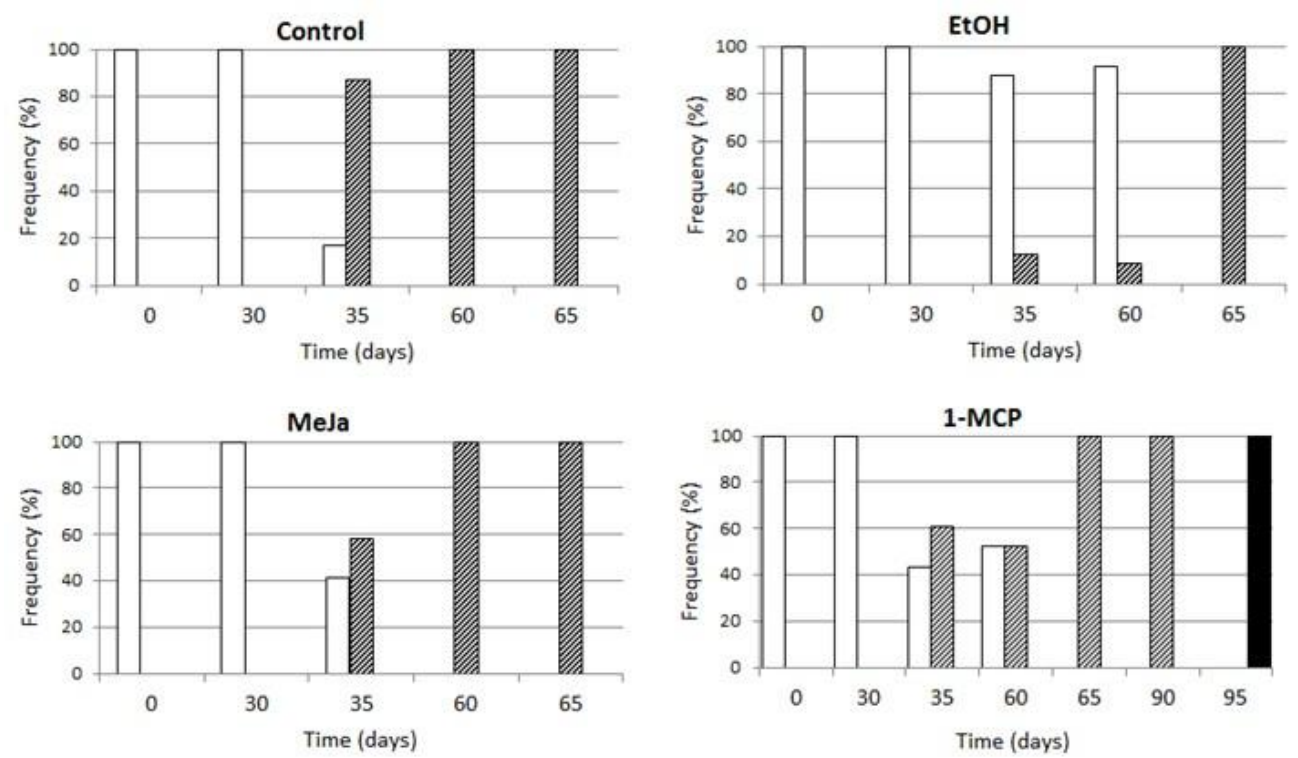

Figure 5. Seed color in 'Bartlett' pears subjected to different volatile treatments, kept at $0 \pm$ $1{ }^{\circ} \mathrm{C}$ and $90 \pm 5 \% \mathrm{RH}$ for up to 90 days and transferred to room temperature for 5 days to ripen (white bars = immature seed, hatched bars = intermediate, black bars = mature seed).
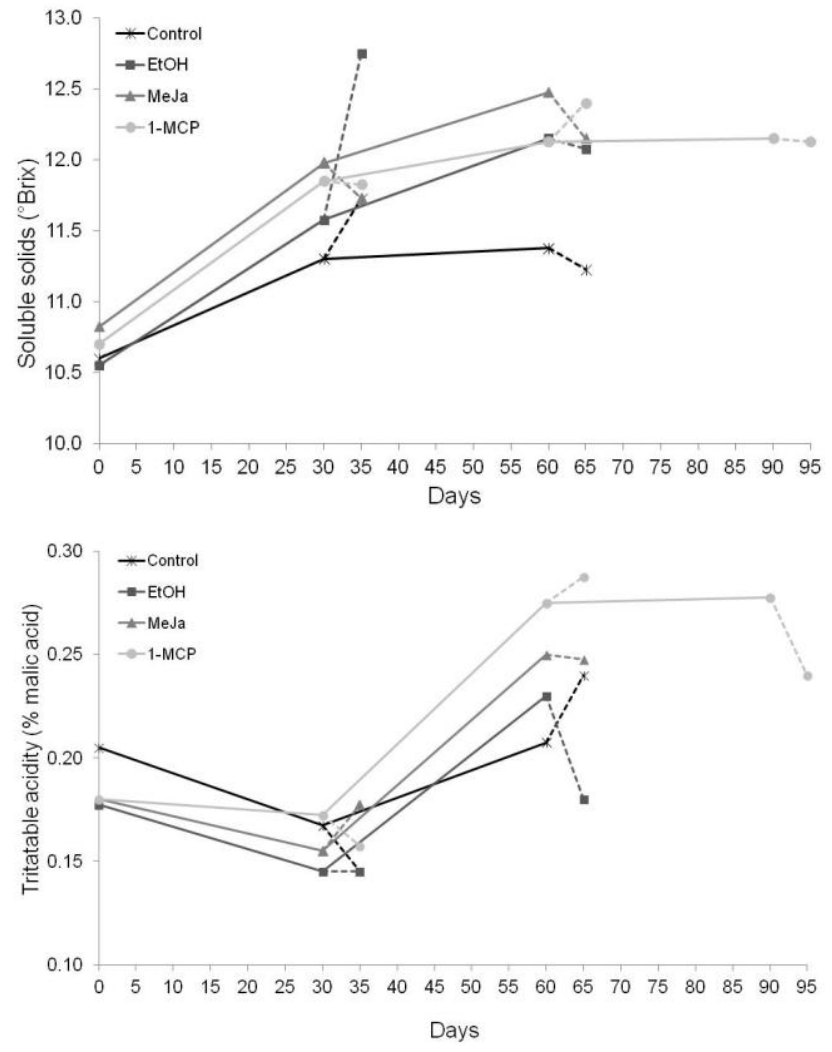

Figure 6. Soluble solids ( ${ }^{\circ}$ Brix) (A) and titratable acidity (\% malic acid) (B) content in 'Bartlett' pears subjected to different volatile treatments, kept at $0 \pm 1{ }^{\circ} \mathrm{C}$ and $90 \pm 5 \% \mathrm{RH}$ for up to 90 days (solid lines) and transferred to room temperature for 5 days to ripen (dashed lines).
1-MCP samples showed $11.8 \%$ of weight loss after 90 days of cold storage followed by 5 days at $20^{\circ} \mathrm{C}$, the same as EtOH-treated pears stored only for 60 days and kept at room temperature for the same period (Table 1 and Figure 7).

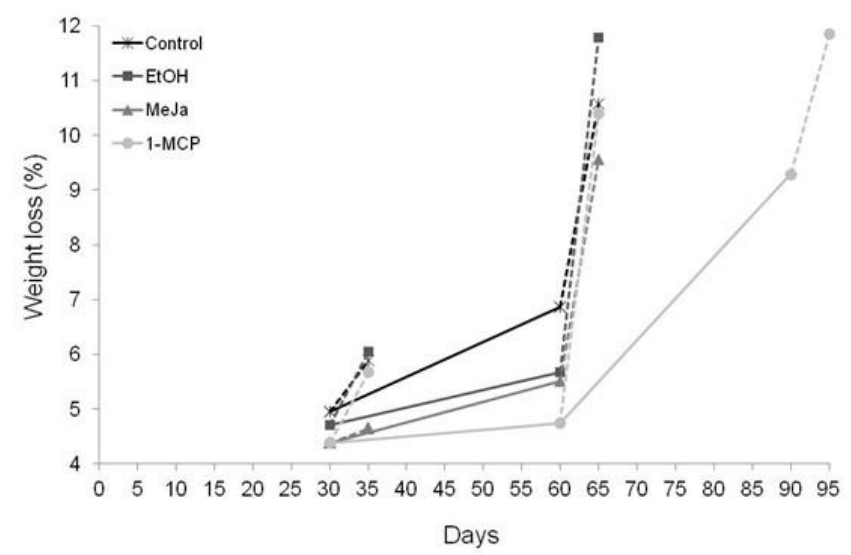

Figure 7. Weight loss (\%) in 'Bartlett' pears subjected to different volatile treatments, kept at $0 \pm 1{ }^{\circ} \mathrm{C}$ and 90 $\pm 5 \% \mathrm{RH}$ for up to 90 days (solid lines) and transferred to room temperature for 5 days to ripen (dashed lines).

EtOH treatment resulted in $92 \%$ of fruit with high peduncle dehydration $(4=90 \%$ dehydrated) after $24 \mathrm{~h}$ exposure volatile treatment. Totally dehydrated peduncles were 
observed in $12 \%$ and $46 \%$ of ethanol-treated fruit stored at $0{ }^{\circ} \mathrm{C}$ for 30 and 60 days, respectively. Control, MeJa and 1-MCP-treated fruit showed fully hydrated peduncles immediately after the volatile treatments but developed dehydration at the cut end after 30 days of cold storage followed by 5 days at room temperature. 1-MCP treatment prevented high peduncle dehydration for up to 60 days of storage and there were no totally dehydrated peduncles after 90 days of storage followed by 5 days at room temperature (data not shown).

Sensory analysis resulted in 1-MCP-treated pears having the highest values for differencefrom-control test after being stored for 30 and 60 days in a cold room followed by 5 days of ripening at room temperature. High acceptance indexes were attributed to MeJa (77.95) and control (76.40) samples after 30 days at cold storage followed by 5 days at room temperature. The greatest acceptance values were attributed to 1-

\section{DISCUSSION}

Disorder symptoms in control, MeJa, and EtOH-treated pears were noticed after 90 days of cold storage, and all the fruit developed internal browning when transferred to $20{ }^{\circ} \mathrm{C}$. Disorder symptoms in 1-MCP-treated pears were observed only after 120 days of cold storage but all the fruit developed the disorder when they were transferred to room temperature and recovered the capacity to ripen. Compared to control, MeJa and EtOH treatments were not able to extend the storage and mitigate the internal browning. 1MCP treatment extended the storage in 30 days, since there were no losses due the disorder up to 90 days of cold storage and in the following five days at room temperature.

Studies by Villalobos-Acuña et al. (2011a) showed that 'Bartlett' pears harvested at harvest maturities of $93 \mathrm{~N}$ and $81 \mathrm{~N}$ flesh firmness exposed or not to 1-MCP $0.3 \mu \mathrm{L} \mathrm{L}-1$ at $20^{\circ} \mathrm{C}$ for 12 $\mathrm{h}$ and kept for up to 180 days at $-1{ }^{\circ} \mathrm{C}$ did not show internal browning after ripening at $20^{\circ} \mathrm{C}$.
MCP-treated pears after 90 days at $0^{\circ} \mathrm{C}$ followed by 5 days at $20^{\circ} \mathrm{C}(89.35)$ (Table 2 ).

Table 2. Difference-from-control test and acceptance test for 'Bartlett' pears subjected to different volatile treatments, kept at $0 \pm 1{ }^{\circ} \mathrm{C}$ and $90 \pm 5 \% \mathrm{RH}$ for up to 90 days and transferred to room temperature for ripening before being supplied to a sensory panel.

\begin{tabular}{ccccc}
\hline & \multicolumn{5}{c}{ Treatments } \\
\cline { 2 - 5 } $\begin{array}{c}\text { Cold storage } \\
\text { (days) + 5 days }\end{array}$ & Control & EtOH & MeJa & MCP \\
\hline & \multicolumn{4}{c}{ Difference-from-control test } \\
\cline { 2 - 5 } 30 & 14.21 & 52.13 & 23.71 & 87.01 \\
60 & 13.50 & 43.16 & 21.42 & 79.28 \\
\cline { 2 - 5 } & \multicolumn{5}{c}{ Acceptance test } \\
\cline { 2 - 5 } 30 & 76.40 & 57.65 & 77.95 & 44.85 \\
60 & 59.31 & 48.45 & 64.71 & 64.38 \\
90 & - & - & - & 89.35 \\
\hline
\end{tabular}

The 1-MCP effects have become more evident when pears from mid-harvest $(76 \mathrm{~N})$ and lateharvest (69 N) were tried and the physiological disorder was completely controlled. In contrast to the findings of Villalobos-Acuña et al. (2011a), 1MCP-treated pears showed disorder symptoms earlier in this experiment. That could be explained by the temperature used during the cold storage, which was $1{ }^{\circ} \mathrm{C}$ higher than that used by Villalobos-Acuña et al. (2011a), although still within the optimal range recommended by the University of California for storage of 'Bartlett' pears (Mitcham et al., 2013). According to Agar et al. (1999), growing region can have an effect on the ripening behavior of pears, even after ethylene or cold storage treatments, and can also affect 1-MCP response.

After 30 days of cold storage, although the mean starch index in 1-MCP-treated samples had reached 9.9, the seeds remained immature and only exhibited changes once fruit were transferred to room temperature. There were no visual changes in the skin color and the flesh did 
not become softer after the pears were transferred to $20^{\circ} \mathrm{C}$. Although the SS content was higher $\left(11.8^{\circ} \mathrm{Brix}\right)$ than that of the control samples (11.3 ${ }^{\circ}$ Brix), 1-MCP-treated pears received the lowest values in the acceptance test and the highest ones in the difference-fromcontrol test. Comments by the panelists which could justify the poor acceptance were high flesh firmness, high acidity and green color of the skin. Villalobos-Acuña et al. $(2011 a, b)$ found that 1MCP $0.3 \mu \mathrm{L} \quad \mathrm{L}^{-1}$ immediately after harvest decreased ethylene production and delayed softening rates and yellow skin color development in 'Bartlett' pears.

After 60 days of cold storage, just $50 \%$ of 1-MCP-treated pears had immature seeds. At the same time, $100 \%$ of the control samples had seeds in a transitional color between beige (immature) and dark (mature). A progression in seed color was observed when 1-MCP samples were transferred to room temperature, accompanied by yellowing of the skin and a marked decrease in flesh firmness. In spite of these samples not reaching the recommended firmness for eating (10-18 N), panelists attributed them high values (index 64.4 in the acceptance test).

After 90 days of cold storage and 5 days at room temperature, having reached $18.7 \mathrm{~N}, 12.1$ ${ }^{\circ}$ Brix and $0.24 \%$ malic acid, 1-MCP-treated pears received the greatest acceptance index (89.3). However, at that stage no fruit from the control or other treatments remained in an acceptable condition for direct sensory comparison with the 1-MCP-treated fruit. Our results have shown the delayed onset of internal browning symptoms are probably more related to delayed ripening than to a direct effect of 1-MCP treatment.

EtOH treatment delayed the development of some quality attributes related to the ripening process, mainly in the beginning of cold storage. Starch breakdown and seed maturation were delayed, resulting in the smallest mean starch index (9.1) after 30 days of cold storage and $87 \%$ of the assessed fruit with beige (immature seeds) after a further 5 days ripening. The pears reached $47.6 \mathrm{~N}$ after 5 days at $20{ }^{\circ} \mathrm{C}$ which was much firmer than the equivalent control fruit and higher than the recommended firmness for eating. On the other hand, no delaying effect was observed on the skin color, which became yellowish, or on the SS content, which increased by $1.2^{\circ}$ Brix during the 5 days ripening at $20^{\circ} \mathrm{C}$. By the end of 60 days of storage plus 5 days at $20^{\circ} \mathrm{C}, \mathrm{EtOH}-$ treated fruit had recovered the full capacity to ripen. Ritenour et al. (1997) did not find significant inhibition of ripening in pears, bananas, honeydews, muskmelons, nectarines, peaches and plums when exposed to ethanol vapors. On the other hand, ripening of tomatoes at various ripening stages was delayed by EtOH vapor treatments (Kelly and Saltveit, 1988; Saltveit and Sharaf, 1992; Ratanachinakorn et al. 1999; Hong et al., 1995). According to Salveit (1989), the delay in ripening is likely to be a result of $\mathrm{EtOH}$ inhibiting the conversion of ACC to ethylene. A harmful dehydrating effect of the ethanol was noticed immediately after the exposure to the volatile treatment when $100 \%$ of the assessed peduncles showed dehydration along at least 50 $\%$ of their length. No symptoms were noticed in the flesh. $46 \%$ of the EtOH-treated pears had totally dried peduncles and reached $12 \%$ of weight loss after being cold stored up to 60 days and transferred to $20^{\circ} \mathrm{C}$. By the end of 60 days of storage plus 5 days at $20{ }^{\circ} \mathrm{C}$ the panelists mentioned a weird, unpleasant, ethanolic taste in the mouth, resulting in the smallest acceptance index (48.4) and indicating there was a distinct difference between those samples and the control ones. Particular fruit structural morphologies such as the stem scar and thin skin favor ethanol diffusion into the internal tissues and can contribute to changes in flavor and taste. As reported by Ratanachinakorn et al. (1999), tomato aroma and flavor were altered in extreme conditions when off-flavors increased.

MeJa treatment caused a slight delaying effect on the starch breakdown and on the color progression of the seeds up to 30 days of cold 
storage followed by 5 days at $20{ }^{\circ} \mathrm{C}$. The flesh firmness values of the MeJa-treated fruit were very similar to those of the control fruit after being transferred to ripen. Despite reaching the ideal eating firmness only after being stored for 60 days, MeJa-treated pears achieved their highest acceptance indices after 30 days (77.95) and 60 days (64.71) of cold storage followed by 5 days at room temperature, presumably as a result of the high SS content primarily. No difference was observed between these samples and the controls, although panelists reported a pleasant flavor in MeJa-treated pears. Reports in the literature have described the impact of $\mathrm{MJ}$ on biosynthesis of volatile compounds in both climacteric fruit, such as apples (Fan et al., 1997; Kondo et al., 2005; Kondo and Mattheis, 2006) and non-climateric fruit, such as strawberries (Fernando Ayala-Zavala et al., 2005; de la Pena Moreno et al.,2010a,b,c).

\section{CONCLUSION}

In conclusion, 1-MCP $0.3 \mu \mathrm{L} \mathrm{L}^{-1}$ vapor treatments for 24 hours at $0 \pm 1{ }^{\circ} \mathrm{C}$ delays ripening and mitigates the internal browning in early harvested 'Bartlett' pears, permitting storage for up to 90 days at $0 \pm 1{ }^{\circ} \mathrm{C}$. The treatment provides 30 days of storage extension with no risk of losses due to internal browning when fruit are transferred to ripen.

\section{ACKNOWLEDGEMENTS}

The authors thank Dr. Keith Robert Sharrock for his suggestions on reviewing the manuscript.

\section{REFERENCES}

Agar IT, Biasi WV, Mitcham EJ (1999) Exogenous ethylene accelerates ripening responses in 'Bartlett' pears regardless of maturity or growing region. Postharvest Biology and Technology, 17: 67-78.
Argenta LC, Fan XT, Mattheis JP (2003) Influence of 1-methylcyclopropene on ripening, storage life, and volatile production by 'd'Anjou' cv. pear fruit. Journal of Agricultural and Food Chemistry, 51: 3858-3864.

Avelar ML, Rodrigues AC (1999) Starch regression test in 'Rocha' pears. Estação Nacional de Fruticultura Vieira Natividade, Sector de PósColheita e Conservação, Alcobaça, Portugal.

Chen PM. Core breakdown. In: Jones $\mathrm{AL}$, Aldwinkle HS (Eds.) Compendium of apple and pear diseases. St Paul, Minn, USA: APS Press, 1990. p. 89.

Creelman RA, Mullet JE (1997) Biosynthesis and action of jasmonate in plants. Annual Review of Plant Physiology and Plant Molecular Biology, 48: 355-38.

Czermainski AC (1999) Generalization of an index of infection intensity in plant disease experiments. Pesquisa Agropecuária Brasileira, 34: 1545-1555.

De la Peña Moreno F, Blanch GP, Flores G, Ruiz del Castillo ML (2010a) Impact of postharvest methyl jasmonate treatment on the volatile composition and flavonol content of strawberries. Journal of the Science of Food and Agriculture, 90: 989-994.

De la Peña Moreno F, Blanch GP, Ruiz del Castillo, $M L$ (2010b) Effect of (-)- and (+)-methyl jasmonate on the formation of aroma-active esters in strawberry fruit. European Food Research and Technology, 231: 829-834.

De la Peña Moreno F, Monagas M, Blanch GP, Bartolomé B, Ruiz del Castillo ML (2010c) Enhancement of phenolic and aroma compounds in strawberry fruit through methyl jasmonate vapor treatment. European Food Research and Technology, 230: 989-999. 
Ekman JH, Clayton M, Biasi WV, Mitcham EJ (2004) Interaction between 1-MCP concentration, treatment interval and storage time for 'Bartlett' pears. Postharvest Biology and Technology, 31: 127-136.

Fan X, Mattheis JP, Fellman JK, Patterson ME (1997) Effect of methyl jasmonate on ethylene and volatile production by Summered apples depends on fruit development stage. Journal of Agricultural and Food Chemistry, 45: 208-211.

Fernando Ayala-Zavala J, Wang SY, Wang CY, González-Aguilar GA (2005) Methyl jasmonate in conjunction with ethanol treatment increases antioxidant capacity, volatile compounds and postharvest life of strawberry fruit. European Food Research and Technology, 221: 731-738.

Ferreira VLP, Almeida TCA, Pettinelli MLC, Silva JBP, Barbosa EMM. Sensory analysis discriminative and affective tests. Campinas, SP, Brasil: SBCTA, 2000.

Franck C, Lammertyn J, Ho QT, Verboven P, Verlinden B, Nicolai BM (2007) Browning disorders in pear fruit. Postharvest Biology and Technology, 43: 1-13.

Hong JH, Lee SK, Kim JK (1995) Ethanol inhibits ripening of tomato fruit. Acta Horticulturae, 398:147-157.

Ju Z, Cury EA, Duan Y, Ju Y, Guo A (2001) Plant oil emulsions prevent senescent scald and core breakdown and reduce fungal decay in 'Bartlett' pears. Journal of the American Society for Horticultural Science, 126: 358-363.

Kelly MO, ME Saltveit Jr (1988) Effect of endogenously synthesized and exogenously applied ethanol on tomato fruit ripening. Plant Physiology, 88:143-147.

Kondo S, Mattheis J (2006) Aroma volatile biosynthesis in apples at harvest or after harvest affected by jasmonates. . Acta Horticulturae, 712: 381-388.

Kondo S, Kittikorn M, Kanlayanarat S (2005) Preharvest antioxidant activities of tropical fruit and the effect of low temperature storage on antioxidants and jasmonates. Postharvest Biology and Technology, 36: 309-318.

Kubo Y, Hiwasa K, Owino WO, Nakano R, Inaba A (2003) Influence of time and concentration of 1MCP application on the shelf life of pear ' $\mathrm{La}$ France' fruit. HortScience, 38: 1414-1416.

Meilgaard MC, Civille GV, Carr BT. Sensory evoluation techniques. FL, USA: CRC Press, 1999.

Mitcham EJ, Crisosto CH, Kader AA (2013) Pear, Bartlett: Recommendations for Maintaining Postharvest Quality. [digital] (August 28, 2013). http://postharvest.ucdavis.edu/PFfruits/PearBartl ett/ [Accessed April 7, 2014].

Pesis E (2005) The role of the anaerobic metabolites, acetaldehyde and ethanol, in fruit ripening, enhancement of fruit quality and fruit deterioration. Postharvest Biology and Technology, 37: 1-19.

Ratanachinakorn B, Klieber A, Simons DH (1999) Ethanol vapor vacuum infiltration of tomatoes: morphological analysis and effect on ripening and eating quality. Journal of the American Society for Horticultural Science, 124: 283-288.

Ritenour MA, Mangrich ME, Beaulieu JC, Rab A, Saltveit ME (1997) Ethanol effects on the ripening of climacteric fruit. Postharvest Biology and Technology, 12: 35-42.

Rudell DR, Mattheis JP, Fan X, Fellman JK (2002) Methyl jasmonate enhances anthocyanin accumulation and modifies production of phenolics and pigments in 'Fuji' apples. Journal of the American Society for Horticultural Science, 127: 435-441. 
Saltveit Jr ME (1989) Effect of alcohols and their interaction with ethylene on the ripening of epidermal pericarp discs of tomato fruit. Plant Physiology, 90:167-174.

Saltveit Jr ME, Sharaf AR (1992) Ethanol inhibits ripening of tomato fruit harvested at various degrees of ripeness without affecting subsequent quality. Journal of the American Society for Horticultural Science, 117:793-798.

Sugar D, Powers KA (1994) Maturity and storage performance of 'Bartlett' and 'Sensation Red Bartlett' pears. HortScience, 29:18-19.

Trinchero GD, Sozzi GO, Covatta, F, Fraschina AA (2004) Inhibition of ethylene action by 1- methylcyclopropene extends postharvest life of 'Bartlett' pears. Postharvest Biology and Technology, 32: 193-204.

Villalobos-Acuña MG, Biasi WV, Flores S, Jiang CZ, Reid MS, Willits NH, Mitcham EJ (2011a) Effect of maturity and cold storage on ethylene biosynthesis and ripening in 'Bartlett' pears treated after harvest with 1-MCP. Postharvest Biology and Technology, 59: 1-9.

Villalobos-Acuña MG, Biasi WV, Mitcham EJ, Holcroft D (2011b) Fruit temperature and ethylene modulate 1-MCP response in 'Bartlett' pears. Postharvest Biology and Technology, 60: 17-23. 